\title{
VISÕES DE AUTONOMIA DO PROFESSOR E SUA INFLUÊNCIA NA PRÁTICA PEDAGÓGICA
}

\author{
Marco Aurélio Alvarenga Monteiro* \\ Isabel Cristina de Castro Monteiro** \\ Tânia Cristina Arantes Macedo de Azevedo***
}

RESUM0: Atualmente muitos trabalhos têm destacado a importância do desenvolvimento da autonomia do professor para a melhoria da qualidade de ensino. Nosso trabalho buscou estudar as concepções sobre autonomia apresentadas por professoras que atuam na Educação Infantil e nas séries iniciais do Ensino Fundamental recém-ingressas no programa de formação de professores Pedagogia Cidadã, oferecido pela Unesp. Nosso intuito é o de compreender como essas concepões contribuíam ou apresentavam obstáculos ao desenvolvimento da profissionalidade docente segundo a visão proposta por Contreras (2002). Os resultados mostraram que as concepções, de natureza altamente individualista e solipsista, apresentadas pelas professoras evidenciam um exercício profissional voltado apenas para questões relativas ao fazer didático-pedagógico de sala de aula.

Palavras-chave: Autonomia; Prática Reflexiva; Formação de Professores.

\section{VISIONS OF AUTONOMY OF THE TEACHER AND HIS INFLUENCE IN PEDAGOGICS PRACTICE}

ABSTRACT: Currently many studies have highlighted the importance of development autonomy of teachers to improve the quality of education. Our study aimed to explore the concepts of autonomy presented that teachers working in kindergarten and first grades of elementary school. Our aim was to understand how these concepões helped or hindered the development of the action of the teacher second Contreras (2002). The results showed that the conceptions, presented by the teacher, were highly individualistic, demonstrate a professional focused only on matters relating to the didactic and pedagogic classroom.

Keyword: Autonomy; Reflexive Practice; Teacher Training.
*Doutor em Educação para a Ciência pela Faculdade de

Ciências (FC) da Universidade Estadual Paulista (UNESP.

Bauru). Professor Colaborador do Instituto Tecnológico de Aeronáutica (ITA) de São José dos Campos. E-mail:

maureliomonteiro@uol.com.br * *Doutora em Educação para a Ciência da Faculdade de Ciências (FC) da Universidade Estadual Paulista (UNESP. Bauru). Professora do Departamento de Física e Química da Faculdade de Engenharia de Guaratinguetá (FEG) da Universidade Estadual Paulista (UNESP)

E-mail: monteiro@feg.unesp.br * * Doutora em Física pela Universidade de São Paulo (USP).Professora do Departamento de Física e Química da Faculdade de Engenharia de Guaratinguetá (FEG) da Universidade Estadual Paulista (UNESP). Diretora Acadêmica da Fundação para o Vestibular da Universidade Estadual Paulista (UNESP) E-mail: tmacedo@feg.unesp.br 


\section{CARACTERIZANDO A AUTONOMIA DO PROFESSOR}

Mesmo sem responsabilizar pessoalmente os professores pela insuficiência da aprendizagem dos alunos, as pesquisas educacionais sempre relacionam o fracasso escolar com a desvalorização do magistério, formação deficiente dos docentes, além dos baixos salários e das precárias condições de trabalho que os professores enfrentam para o desenvolvimento de suas práticas pedagógicas. Nesse sentido, além de uma postura mais ativa no âmbito político, que transcende o espaço da escola, na qual o professor deve atuar para exigir do poder público maior compromisso com a educação, muitos trabalhos de pesquisa têm sinalizado para a importância de uma reformulação dos cursos de formação inicial e da intensificação dos cursos de formação continuada.

Uma das exigências atuais sobre a escola, no sentido de formar o cidadão crítico e participativo, tem criado um consenso em torno da ideia da democratização da gestão escolar. Para Luck (2000), há uma tendência mundial de globalização no que diz respeito ao conceito de autonomia escolar. Nesse novo paradigma, que tem gerado impactos significativos nas concepções de gestão educacional e nas ações dela decorrentes, novos conceitos são apresentados como fundamentos dos processos decisórios do contexto escolar, tendo em vista a formação e a mobilização de massa crítica para promover a transformação e a sedimentação de novos referenciais que sustentem ações capazes de atender às novas necessidades de formação social a que a escola deve responder.

Monteiro (2006) evidencia que condicionantes próprios da identidade docente interferem decisivamente na maneira como professores dirigem atividades que inovam sua prática em sala de aula. $\mathrm{O}$ autor destaca que, num curso de formação continuada voltado para professoras das séries iniciais do Ensino Fundamental, em que foi discutida uma proposta de ensino de Ciências, as inovações sugeridas e estudadas coletivamente foram adotadas até quando o pesquisador esteve junto com as docentes no âmbito escolar. Um ano após seu afastamento, as professoras haviam retornado às práticas didático-pedagógicas anteriores. As docentes justificaram que abandonaram as práticas de ensino inovadoras tendo em vista a insegurança que sentiram pela não presença do pesquisador junto a elas orientando suas ações.

Esse fato destaca a importância de que cursos de formação inicial e continuada de professores possam não apenas se preocupar com os conteúdos didáticos pedagógicos dos conceitos científicos que ensinam, mas que também possam dedicar atenção ao desenvolvimento da autonomia do professor para que haja uma sustentabilidade de ações que se busca implementar em nossas escolas.

A nosso ver, isso se torna ainda mais urgente quando nos referimos ao ensino de Ciências nas séries iniciais do Ensino Fundamental, tendo em vista a insegurança que as professoras generalistas sentem diante do desafio de abordarem temas que envolvam conceitos científicos. É exatamente nesse contexto que a autonomia se mostra como uma questão de importância primordial. 
Segundo o Novo Dicionário Aurélio de Língua Portuguesa (1986), autonomia pode apresentar os seguintes significados:

Faculdade de se governar por si mesmo; direito ou faculdade de se reger (uma nação) por si próprio; liberdade ou independência moral ou intelectual; propriedade pela qual o homem pretende escolher as leis que regem sua conduta (p. 203).

Essas definições evidenciam uma concepção individualista, segundo a qual cada indivíduo agiria e/ou pensaria com plena independência, em relação tanto a outros indivíduos quanto a qualquer contexto.

Em contraposição a essa ideia, Bobbio (2000 apud MARTINS, 2002) destaca que a concepção individualista que deu origem ao conceito de autonomia contraria não somente a concepção de sociedade primitiva do sujeito soberano, na qual as decisões políticas se davam sem intermediários, como também a noção de sociedades modernas, complexas e extremamente burocratizadas. Para esse autor, os protagonistas da vida política de uma sociedade não são os sujeitos individuais, mas os grupos que a compõem.

Desse ponto de vista, a autonomia é compreendida como um processo de relação no qual diferentes grupos que compõem uma sociedade negociam seus diversos interesses, tanto particulares quanto gerais. Nessa direção, Martins (2002) a vê como uma construção histórica influenciada por fatores culturais, econômicos e políticos que determinam a sociedade no decorrer de sua existência. Assim, para a autora, é necessário discutir primeiramente seu significado segundo os pontos de vista histórico, político e filosófico, para depois compreender seu conceito no âmbito dos discursos das políticas públicas para a educação.

No entender de Castoriadis (1991), a autonomia é o pressuposto e, ao mesmo tempo, o resultado da ética e, portanto, só pode ser definida na relação social. Desse modo, a autonomia passa a ser um instrumento necessário à sociedade quando esta pressiona as instituições em busca de soluções urgentes para os problemas e conflitos que todos vivenciam. Essa pressão, então, é exercida objetivando uma tomada de decisão no sentido de promover as transformações e/ou mudanças sem perder o momentum ideal, e isso depende da participação coletiva (LUCK, 2000).

O conceito de sujeito autônomo, portanto, envolve a ideia de responsabilidade social, pois requer compromisso daqueles que participam do processo decisório com questões que vão além de seus próprios interesses. Por isso, longe de ser um empreendimento individual, a atitude autônoma necessita estar vinculada a uma sensibilidade capaz de entender o outro e com disposição para a busca do consenso social.

Dessa forma, não se pode analisar a autonomia por uma ótica individualista ou psicologista. Como afirma Contreras (2002), a autonomia, tal como valores morais, não é uma capacidade individual, mas se constitui num exercício, 
numa prática social. Portanto não faz sentido falar que alguém é ou não autônomo, mas que há processos ou situações nas quais pessoas agem de maneira autônoma.

Para Martins (2002), o motor da ação é o desejo da participação. Nesse sentido é possível considerar uma participação positiva e outra negativa. A primeira, caracterizada pelo desejo em participar, atuar, envolver-se com as questões em foco e comprometer-se com a busca por soluções para os problemas encontrados. A segunda, evidenciada pela obrigação normativa, delegada por instâncias superiores e/ou regras institucionais.

Dessa forma, não se consegue uma participação positiva com a existência de processos impositivos e/ou limitadores de ações decorrentes de relações hierarquizadas entre aqueles que buscam soluções para os problemas que se quer superar. A hierarquia inviabiliza um engajamento mais intenso do participante, tendo em vista que este se encontra limitado por normas institucionais e não se sente à vontade para opinar sobre assuntos que, pela regra hierárquica, não são de sua competência. É nesse contexto que surgem atitudes tais como: "Isso não é comigo...", “A minha parte eu fiz...", "Eu não ganho para isso...", entre outras (MONTEIRO, 2006).

Mas como os professores interpretam uma ação autônoma para o trabalho docente? Quais obstáculos os professores têm enfrentado para o exercício mais autônomo de sua profissão? Essas são questões que, para serem respondidas, é necessário que investiguemos algumas variáveis que, a nosso ver, interferem na maneira como o professor encara o significado de sua profissão, que por sua vez tem vínculos com os processos de formação de sua identidade docente.

\section{A FORMAC̣ÃO DA IDENTIDADE DO PROFESSOR}

Os processos de racionalização pelos quais passou a profissão docente limitaram o papel do professor e sua função no ensino. Os modelos tayloristas e fordistas, aplicados nas indústrias objetivando a homogeneização do trabalho com vista à redução de custos e maior produtividade, transcenderam a sua atuação e condicionaram a prática docente à posição de consumidores e não de criadores. Nessa direção, o professor viu seu papel profissional reduzido ao de um técnico, aplicador de programas e pacotes curriculares, diante do grau de detalhamento dos currículos (CONTRERAS, 2002).

Neste aspecto, Contreras (opus cit.) busca separar o significado de profissionalização e profissionalismo do professor. Enquanto a profissionalização é concebida em função de mudanças socioeconômicas relativas ao processo de proletarização do professor, o qual teve suas funções e atribuições reduzidas a um mero reprodutor de fórmulas preestabelecidas, a profissionalidade relacionase com a maneira pela qual o professor exerce sua função. 
Nessa perspectiva, o autor analisa a questão da autonomia a partir de três aspectos que julga fundamentais para caracterizar mais precisamente a profissão docente, no sentido de especificá-la enquanto exigências do trabalho educativo: a obrigação moral, o compromisso com a comunidade e a competência profissional.

Para Contreras (opus cit.), a obrigação moral é a dimensão da profissão docente que requer um compromisso de caráter moral, tendo em vista que a educação está relacionada com a ideia de formação do indivíduo, não apenas no que diz respeito ao aspecto intelectual, mas de forma plena e total.

Esta especificidade do trabalho docente marca implicitamente o papel do professor, independentemente de cláusulas contratuais ou compromissos formalmente determinados. Assim, acima de conhecimentos específicos e preparação intelectual do professor, sua imagem está intimamente relacionada à ideia de alguém que está, ou deveria estar, compromissado com o desenvolvimento dos alunos como seres humanos livres, autônomos e dotados de valores morais prezados pela sociedade.

Mesmo que os professores não tenham compromisso consciente com esta dimensão de sua profissionalidade, suas ações dentro ou fora da sala de aula têm consequências de caráter moral, haja vista a natureza dos vínculos emocionais e afetivos que se estabelecem entre ele e seus alunos.

Sem dúvida, o compromisso moral implicitamente assumido pelo professor está relacionado com sua visão de mundo e sua identidade pessoal e, muitas vezes, entra em choque com orientações e exigências institucionais. Dessa forma, essa questão esbarra fortemente na definição de autonomia docente, pois é um compromisso profissional que deve ser resultado de reflexão e negociação de modo a superar múltiplos conflitos que nascem das diferenças de perspectivas tanto dos professores quanto destes para com os alunos e a comunidade.

Outro aspecto da profissionalidade docente destacada pelo autor é o compromisso com a comunidade. Como já frisamos, a função de educador não pode ser encarada como prática isolada. Como as ações de um educador têm um apelo ético extremamente amplo, pois não lida com máquinas ou coisas, mas com pessoas em formação e, portanto, sensíveis, seus valores estão em constante conflito com padrões de comportamento que surgem na sociedade, principalmente nestes tempos de pós-modernidade, na qual a crise de paradigmas parece ser a norma.

Assim, na visão do autor, a moral não é uma característica pessoal ou individual, mas é construída socialmente e, portanto, com caráter político. Essa realidade obriga o professor a estabelecer uma relação constante com a sociedade para que possa compartilhar com ela a construção desses valores que condicionam sua prática profissional.

Isso não se constitui em tarefa fácil, pois os processos de deliberação moral não se dão de forma linear pela aplicação de regras e normas. $\mathrm{Na}$ verdade, esses processos se estruturam de maneira conflituosa e até mesmo de forma 
contraditória, pois envolvem interpretações e juízos de valores dos diferentes professores e dos diferentes representantes da comunidade escolar, além dos segmentos provenientes da sociedade na qual a escola está inserida.

Finalmente, o terceiro e último aspecto da profissionalidade docente destacado por Contreras (2002) refere-se à competência profissional. Essa dimensão envolve os conhecimentos científicos e as habilidades e técnicas em geral relativos aos recursos da ação didática. Contudo, tendo em vista os dois aspectos anteriores, a profissão docente exige uma competência que extrapola os domínios intelectivos e técnicos desenvolvidos apenas na universidade nos cursos de formação.

Essa competência docente está relacionada com a capacidade do professor em interagir com o meio social no qual desempenha sua função de forma a respeitar as individualidades, ter sensibilidade para considerar as necessidades alheias, mesmo que estas lhe pareçam pouco importantes, estabelecer vínculos de afetividade e confiança, além de ter bom senso para ponderar sobre os múltiplos problemas que condicionam o fazer pedagógico e exigem intuição e capacidade de improvisação.

Diante do exposto, temos que a autonomia do professor envolve um trabalho reflexivo e crítico do docente sobre aspectos próprios das diferentes dimensões de sua profissionalidade. Assim, como destaca Magnani (1993), o professor se forma no trabalho, movido por utopias e sobressaltos nascidos dos embates das relações que se estabelecem na prática e no convívio com as múltiplas variáveis que definem o contexto educacional.

Contudo, se esse trabalho e esses embates não forem objeto de reflexão e crítica por parte do professor, não teremos um profissional com identidade autônoma. Dessa forma, o exercício autônomo da docência está amplamente relacionado com consciência e a vivência do professor com toda as dimensões de sua profissionalidade.

A partir dessas considerações, nosso trabalho busca caracterizar a concepção de autonomia que um grupo de professoras-alunas apresenta e como essas concepções influenciam o fazer pedagógico dessas docentes em sala de aula. Nossa amostra de investigação são professoras-alunas ingressantes do programa Pedagogia Cidadã, oferecido pela Universidade Estadual Paulista Júlio de Mesquita Filho (Unesp) para as redes municipais do estado de São Paulo, com o objetivo de formação de professores que atuam na Educação Infantil e nas séries iniciais do Ensino Fundamental.

\section{A PESQUISA}

O Pedagogia Cidadã foi um projeto de formação de professores desenvolvido pela Unesp que dispunha de diferentes recursos: tecnológicos de informação e comunicação (teleconferências, videoconferências e internet) e 
didáticos (material impresso com conteúdo diversificado e independente, além de vivências pedagógicas). O curso era voltado para professores da Educação Infantil e das séries iniciais do Ensino Fundamental que não tinham formação em nível superior, mas que apresentavam experiências significativas com o exercício da docência.

Neste trabalho, ao investigarmos as concepções de autonomia das professoras recém-ingressas no curso Pedagogia Cidadã, temos o intuito de discutir a importância que cursos de formação inicial e continuada de professores devem dar ao desenvolvimento da autonomia profissional dos docentes.

No curso Pedagogia Cidadã, era de se esperar que as professoras-alunas, com ampla experiência no ensino, apresentassem uma autonomia profissional mais desenvolvida. Nesse sentido, quais eram as expectativas dessas professoras em torno do curso em que estavam ingressando? Quais as contribuições que o curso poderia, de fato, oferecer à prática docente daquelas professoras? Será que elas estavam prontas para discutir a prática docente que desenvolviam em sala de aula ou esperavam do curso uma receita de como ensinar?

\subsection{Metodologias de coleta e análise de dados}

Nossa investigação direcionou especial atenção às narrações de memórias feitas por professoras sobre suas trajetórias profissionais, visando a extrair delas evidências que explicitassem dados da identidade profissional de cada docente, permitindo-nos, portanto, inferir suas concepções sobre o exercício autônomo do fazer pedagógico.

Os dados de nossa pesquisa foram coletados a partir da narração de memórias escritas pelas professoras-alunas do curso Pedagogia Cidadã - unidade de Campos do Jordão, relativas às suas experiências com o ensino de ciências, tanto na condição de professoras como na de alunas.

O processo de produção das memórias das professoras-alunas participantes de nossa pesquisa foi estabelecido mediante solicitação de um dos autores deste trabalho, que também era professor-orientador da turma, que apresentava suas impressões sobre o texto produzido e os devolvia, estimulando-as a complementar informações, a resgatar mais profundamente impressões mais detalhadas guardadas em suas memórias. De um total de 40 professoras-alunas estimuladas a escrever sobre suas experiências com o ensino de ciências, 22 se colocaram à nossa disposição.

A análise dos dados é feita em função da identificação de concepções apresentadas pelas professoras e categorizadas segundo aspectos das dimensões da profissionalidade propostas por Contreras (2002), buscando caracterizar como essas concepções limitam ou contribuem para ações docentes mais autônomas. 


\title{
4. DISCUSSÃO DOS RESULTADOS
}

Ao analisarmos as narrações de memórias das professoras referentes às suas experiências com o ensino, seja na condição de alunas, seja na condição de professoras, no decorrer da carreira profissional, identificamos uma concepção solipsista sobre o exercício autônomo da docência.

Para as professoras, como podemos verificar nos excertos de algumas narrativas de memórias apresentados a seguir, o exercício autônomo da profissão está relacionado com "um saber fazer" sozinho, independentemente dos outros e de contextos.

\begin{abstract}
Prof. 1 - Agora eu me acho com mais autonomia. Mas antes, quando eu comecei, eu nem sabia bem o que fazer em sala de aula. Graças a Deus eu tive uma diretora muito boa que me ajudou muito a preparar as aulas, as atividades, a trabalhar. Hoje, depois de 15 anos de experiência eu já sei fazer.

Prof. 2 - Eu sempre fui autônoma na minha escola. Sempre fiz o que eu achava que tinha de fazer, o que eu queria. Mas ultimamente isso tem mudado.

Prof. 3 - Neste país não há respeito pela profissão e autonomia do professor (...). (...) O direito e a escolha de como se vai avaliar um aluno é única e exclusivamente do professor, pois é ele quem convive, quem ensina e quem, portanto, sabe exatamente das dificuldades e avanços de cada aluno. Então, se o aluno progrediu ou não, isso pertence ao professor e a mais ninguém. Eu sei e, portanto, sou eu e mais ninguém quem deve escolher os critérios e os instrumentos de avaliação. Qualquer interferência nisso significa perda de autonomia.
\end{abstract}

Nessas falas, percebe-se que as professoras apresentam uma visão de autonomia na qual se crê na possibilidade de exercer sua função profissional de forma absoluta, sem levar em conta a necessidade de uma ressignificação da profissão e das expectativas sociais em torno dela, à medida que transformações sociais se estabelecem e novas exigências são feitas em relação à escola.

Nesse aspecto, as professoras resistem à aceitação de ingerências externas ao seu trabalho, justificando que sabem, que conhecem e, dessa forma, deixam transparecer, apesar de tal concepção estar implícita em seus dizeres, que, se não soubessem, se não conhecessem, tal ingerência seria possível. Isso nos permite concluir que, no entender das professoras, a autonomia é um "fazer sozinho", independente, sem ingerências externas, que se alcança a partir da conquista de um saber, de um conhecer.

Essa concepção solipsista de autonomia permite ao professor resistir às mudanças que se busca implementar nas escolas. Apesar de ser entendida, muitas vezes, como algo negativo, essa resistência, a nosso ver, evidencia-se como uma reação docente à preservação de sua identidade profissional, e é graças a ela que muitos modismos pedagógicos têm tido pouca penetração em nossas escolas.

Contudo, como destaca Contreras (2002), a autonomia, assim como valores morais, não diz respeito à capacidade individual, mas constitui-se numa 
prática social. Portanto, essa concepção solipsista apresenta-se como uma ilusão, pois ao entenderem a autonomia como ações que não dependem de outros fatores se não aqueles relativos ao conhecimento, ao saber, as professoras não permitem a si próprias vivências de embates reflexivos e críticos com a comunidade na qual estão inseridas e trabalham.

Esse fato, na visão de Contreras (opus cit), limita um exercício mais amplo de sua profissionalidade, pois não permite o desenvolvimento da dimensão relativa ao compromisso com a comunidade. Além disso, há que se levar em conta que, como destaca Pimenta (2000), toda profissão só tem significado quando tem reconhecimento social. Assim, o exercício profissional do professor é altamente influenciado por transformações por que passa a sociedade e, dessa forma, querendo ou não, decisões que são determinadas em escala macroscópicas, entre as nações, por exemplo, modificam a realidade microscópica da sala de aula onde estão o professor e seus alunos.

Dessa forma, alheias a essa questão, as professoras deixam de vivenciar situações que permitem o desenvolvimento da dimensão da profissionalidade docente relativa ao compromisso com a comunidade e, assim, perdem a oportunidade de negociar interdependências a que todos, qualquer que seja a profissão, estamos submetidos. Mais especificamente em relação ao ensino de Ciências, não basta que os professores saibam os conteúdos e dominem um fazer pedagógico que envolva práticas experimentais e o uso de novas tecnologias.

Muitos professores participam de cursos de formação continuada fora da escola e recebem orientações quanto ao desenvolvimento de atividades didáticas em sala de aula. Contudo, quando voltam para a escola se frustram ao tentarem implementar, sozinhos, sem uma negociação com os outros membros da comunidade a que pertencem, as modificações necessárias.

Esse aspecto fica claro na fala das professoras:

Prof. 3 - Eu participo de todos os cursos que aparecem. Sou dedicada, busco aprender bem as coisas para levar para meus alunos. Mas o que adianta isso? Quando chega à escola eles não oferecem estrutura para a gente desenvolver nosso trabalho.

Prof. 4 - Eu sei usar computador em sala de aula. Aprendi a fazer umas atividades com os alunos. Mas pergunta se eu faço. Não tenho o computador disponível para fazer as atividades. O que se vai fazer?

Prof. 6 - Teve uma época que sempre entrava nesses sites que ensinam a fazer experiência. Sabe? Então... Mas não tem material, os alunos não trazem, os pais reclamam. Aí, sem apoio, a gente desiste. É melhor fazer o arroz com feijão mesmo.

A falta de consciência de que a autonomia, como destaca Castoriadis (1991), é um conceito relacional, ou seja, não há como ser totalmente independente do outro, impede as professoras de desenvolverem uma maior consciência sobre os mecanismos de interdependências a que estão submetidas.

Esse fato as impossibilita de participarem das decisões e das negociações que irão interferir na maneira como elas gerem o ensino em sala de aula. 
Em outras palavras, por terem uma concepção de autonomia relacionada a uma visão solipsista, as professoras deixam de ocupar um espaço próprio de uma das dimensões da profissionalidade docente, denominado competência profissional, e assim, ironicamente, limitam sua real autonomia.

Aliás, com relação a essa dimensão da profissionalidade docente, a competência profissional, os excertos destacados a seguir evidenciam outros aspectos importantes.

Prof. 4 - A gestão da escola é com a direção e a coordenação. Por isso elas estão fora da sala de aula. Mas na minha sala eu faço aquilo que eu acho que tenho que fazer e pronto! Eu tenho direito, pois sou uma profissional.

Prof. 3 - Tem coisa que a gente vê que está errado mas vai fazer o quê? A gente faz o que pode. Falar eu até falo, mas tem coisa que está fora do alcance da gente, não nos compete. Já me chateei muito com isso. Agora, não! A gente aprende. Por isso cumpro meu papel, faço o meu melhor, com carinho, dedicação e muita seriedade, procurando sempre melhorar.

Como, para Contreras (2002), a dimensão da competência profissional do professor vai além do domínio dos conhecimentos científicos e de habilidades e técnicas didáticas em geral, englobando, também, uma capacidade de interagir com o meio social onde desenvolve seu trabalho, ao limitar-se ao exercício de sala de aula, as professoras perdem a oportunidade de desenvolverem essa dimensão de uma profissionalidade.

Por sentirem que não lhes competem, ou seja, que não fazem parte de sua competência profissional, ações de decisão externas aos limites de sala de aula, adotam, muitas vezes, uma postura que podemos classificar, segundo a proposição apresentada por Martins (2002), de participação negativa, obedecendo a uma obrigação normativa sem se comprometerem com os resultados da ação.

Essa participação negativa fica clara diante dos excertos a seguir, nos quais as professoras relatam que preparam as reuniões de pais por mero cumprimento daquilo que foi estabelecido, pois não acreditam na finalidade delas. Destacam também que os cursos que frequentam de nada servem, pois não são proporcionadas oportunidades para colocarem em prática aquilo que puderam aprender.

Prof. 4 - Muitas dificuldades seriam superadas se tivesse maior participação dos pais, mas eles não estão nem aí. A reunião de pais seria importante, mas não é, porque os pais que precisam vir nunca aparecem. Aqueles que não precisam vir estão sempre lá, mas aí não adianta. A gente prepara as reuniões porque tem que preparar, mas isso não me anima não. Eu já sei que não vai dar certo.

Prof. 3 - Em relação aos cursos que o município nos oferece, realmente, alguns são muito bons. Não há como negar o alto nível da qualidade dos profissionais que ministraram as palestras. Mas não adianta nada porque a gente volta para a escola e tenta aplicar o que aprendeu, mas não encontra apoio. Eu acho inaceitável isso. Como pode a Secretaria da Educação investir em palestras e cursos, mas em contrapartida obrigarnos a fazer tudo ao contrário? 
Prof. 1 - Tem curso que é bom e outros que não são bons não. Mas todos eles, até os bons, não levam em conta as dificuldades que a gente tem que enfrentar. Aí, como a gente tem que ficar fazendo adaptação, dando um jeitinho, acaba desanimando e fazendo do jeito que a gente sempre fez.

Em outras palavras, o que se percebe é que, ao crerem que a ação do professor se restringe ao espaço limitado de sala de aula, as professoras negam a dimensão profissional da docência que lhes atribui a competência para, juntamente com a direção, pais, alunos e demais professores, participarem de decisões que determinam ações que envolvem e responsabilizam a todos em torno de resultados comuns.

Essa nossa percepção é confirmada diante da indignação que as professoras mostram quando sentem interferências no seu fazer pedagógico dentro de sala de aula, apesar de aceitarem as interferências externas.

\begin{abstract}
Prof. 3 - Nessa escola era simplesmente horrível. Sempre confiaram no meu trabalho e imagine que eu naquele momento não estava tendo liberdade para fazer o meu trabalho. Era sempre a mesma coisa, ou melhor, a mesma "podação": definiam que eu tinha que cantar musiquinhas toda semana, fazer apresentações em todas as datas comemorativas, fazer murais, ter que enfeitar a escola nas datas comemorativas, tudo isso, sem ter um objetivo ou a participação e o envolvimento dos alunos. Mas, até aí, tudo bem! A direção quer a apresentação na escola, a gente aceita e faz. Mas o que não dava para engolir é, obrigatoriamente, a gente ter que fazer o caderno volante, onde cada dia um aluno escrevia a matéria do dia neste caderno e o caderno do aluno ficava em branco, pois era por esse caderno que a diretora e a coordenadora controlavam se nós, professoras, estávamos fazendo o que tinha sido determinado nas reuniões.

Prof. 3 - (...) eu dava aula de Educação Física na época e, como a quadra estava impossibilitada de ser utilizada, a gente ficava de mãos atadas. Sugeri que os alunos fizessem caminhadas no entorno da escola, encaminhei projeto para a diretora e cartas aos pais pedindo permissão. Não era só o exercício da caminhada. Nesse passeio entre aspas, a gente tinha oportunidade de discutir geografia, história, ciências, etc. Como resposta? Ouvi que era melhor deixar que os alunos ficassem jogando pingue-pongue mesmo. Não desanimei, reclamei, bati o pé, insisti. Mas não adiantou nada! A diretora disse que um dos alunos era office-boy e, portanto, já caminhava bastante, sendo desnecessária aquela atividade que eu havia proposto. Aí vai se fazer o quê? A diretora era ela e eu só a professora.
\end{abstract}

No episódio do caderno volante a professora se mostra revoltada e considera que houve limitação em sua autonomia, apesar de achar normal a diretora exigir atividades que ela não julgava ideal. Já na questão das caminhadas no entorno da escola, a professora afirma ter insistido. Contudo, deixa transparecer a concepção de que era "só uma professora" e, portanto, sem competência para decidir ou, pelo menos, para interferir na decisão.

Esses fatos denunciam a verticalidade das relações que se estabelecem na estrutura escolar, que impede uma participação positiva dos professores nas decisões e ações da gestão escolar. Como bem destaca Luck (2000), a autonomia 
envolve uma mobilização de todos no processo de tomada de decisão. E isso envolve, necessariamente, uma descentralização do poder.

Desse ponto de vista, professores, coordenadores e diretores devem se envolver em discussões, a fim de encontrarem uma solução negociada para os problemas que surgem no cotidiano escolar. Esse processo só é possível se as relações forem horizontalizadas.

A fala das professoras em suas narrações de memórias mostra um professor isolado e ao mesmo tempo cercado por problemas, exigências, cobranças e um imenso trabalho burocrático e isolado de ajuda, apoio e, acima de tudo, de si mesmo, pois às vezes se mostra em crise com o significado de seu exercício profissional.

Prof. 3 - Por isso que eu estou cansada de ser professora. É que não sei fazer outra coisa. O médico sabe o que ele tem que fazer. Ele aprende porque dizem para ele o que tem que fazer e ele faz. De tempos em tempos vai a um congresso e volta sabendo o que tem de fazer sobre essa ou aquela doença. Assim, é o engenheiro, o carteiro, o cozinheiro. Por que com o professor é essa complicação?

Prof. 1 - Quando eu fiquei sabendo da possibilidade de fazer esse curso, eu já fiquei superansiosa. Eu sabia que aqui eu teria a chance de aprender a ser uma professora que faz a diferença para seus alunos.

Diante disso, acreditamos que outra dimensão da profissionalidade docente destacada por Contreras (2002) que se mostra limitada é aquela que se refere ao compromisso moral. $\mathrm{O}$ isolamento no qual as professoras se encontram acaba por afastá-las dos valores e dos princípios que permeiam a comunidade escolar na qual lecionam e, dessa forma, muitas de suas crenças, de seus propósitos e objetivos pessoais e profissionais entram em conflito com aqueles definidos pela instituição, ou seja, com os valores dos outros professores, da direção, da coordenação, dos pais, dos alunos, etc.

Além disso, é preciso destacar que, segundo Contreras (opus cit), a dimensão moral da profissionalidade docente envolve questões afetivas e emocionais. A fala da professora que revela seu "cansaço" com o exercício da docência evidencia uma crise emocional do professor com sua função em sala de aula.

É preciso destacar também que as professoras apresentavam uma expectativa em relação ao curso em que ingressavam fundada na ideia de que receberiam uma receita de como ministrar as aulas. Nesse sentido, de uma forma geral, parece ser necessário que as professoras-alunas tivessem a oportunidade de ressignificar o conceito que apresentam sobre autonomia profissional, a partir do desenvolvimento da consciência de outras dimensões da profissionalidade docente. Mas, para isso, é necessário que o curso, seja ele de formação inicial ou continuda, leve em conta a importância dessas dimensões da profissionalidade docente e essas necessidades do professor. 


\section{CONSIDERAC̣ÕES FINAIS}

Nosso trabalho buscou estudar as concepções sobre autonomia que professoras-alunas recém-ingressas no programa Pedagogia Cidadã evidenciavam. Os resultados mostraram que as concepções, de natureza altamente individualista e solipsista, apresentadas pelas professoras-alunas evidenciam um exercício profissional voltado apenas para questões relativas ao fazer didático-pedagógico de sala de aula.

Essa realidade chamou-nos a atenção para intensificar, durante o curso de formação, atividades reflexivas relativas às dimensões da profissionalidade docente que vão além do domínio conceitual daquilo que vão ensinar e das diferentes metodologias e estratégias a serem utilizadas no processo de ensino e de aprendizagem com os alunos em sala de aula.

Assim sendo, o trabalho tornou urgente a necessidade de empregarmos esforços que fossem além de atividades didáticas e que propiciassem reflexões na e sobre a ação. Constatamos a importância de oferecermos às professoras-alunas oportunidades de uma reflexão crítica sobre a natureza das ações próprias das dimensões do exercício profissional da docência, para que elas pudessem ter, em todas as atividades do curso de formação, a oportunidade de dialogar, como indica Alarcão (2003), consigo mesmas, com o problema, a situação a ser enfrentada e com o outro, ou os outros que partilham conosco a realidade do espaço escolar.

Em trabalhos futuros temos a intenção de caracterizar a evolução das concepções apresentadas pelas professoras-alunas, buscando evidenciar aspectos das trajetórias percorridas por elas durante a realização do curso em atividades de Ciências que desenvolveram com seus alunos em condições reais de sala de aula. A evolução dessas concepções se mostrara decisiva para a superação dos limites que detectamos neste estudo inicial. 


\section{REFERÊNCIAS BIBLIOGRÁFICAS}

ALARCÃO, I. Professores reflexivos em uma escola reflexiva: questões de nossa época. São Paulo, Cortez, 2003.

BOBBIO, N. O futuro da democracia. Rio de Janeiro: Paz e Terra, 2000.

CASTORIADIS, C. A instituição imaginária da sociedade. Rio de Janeiro: Paz e Terra, 1991.

CONTRERAS, J. Autonomia de professores. São Paulo: Cortez, 2002.

LÜCK, H. "Perspectivas da gestão escolar e implicação quanto à formação de seus gestores". In: Aberto, Brasília, v. 17, n. 72, fev-jun. 2000, p. 11-33.

MARTINS, A. M. "Autonomia e educação: a trajetória de um conceito". In: Cadernos de Pesquisa, São Paulo, n. 115, 2002, p. 207-232.

MONTEIRO. M. A. A. Um estudo da autonomia docente no contexto do ensino de ciências nas séries iniciais do Ensino Fundamental. 305 f. Tese (Doutorado em Educação para a Ciência). Faculdade de Ciências, Universidade Estadual Paulista, Bauru, 2006.

PIMENTA, S. G. "Formação de professores: identidade e saberes da docência". In: PIMENTA, S. G. (org.). Saberes pedagógicos e atividade docente. São Paulo, Cortez, 2000.

SCHÖN, D. "Formar professores como profissionais reflexivos". In: Nóvoa, A. (org.). Os professores e sua formação. Lisboa: Dom Quixote, 1997. 